\title{
Conversion of the Communication Paradigm for People at the End of Their Life
}

\author{
Yasuko Fukaya* \\ Department of Nursing, Kanto-Gakuin University, Japan
}

Received: May 15, 2017; Accepted: May 22, 2017; Published: May 26, 2017

*Corresponding author: Yasuko Fukaya, phD, Kanto-Gakuin University, Department of Nursing, 1-50-1 Mutuura-Higashi, Kanazawaku, Yokohama, Kanagawa, 236-8503, Japan, Tel and Fax: +81-045-786-5693; E-mail: yafukaya@kanto-gakuin.ac.jp

\section{Dear Editor}

Communication is indispensable to nursing practice, and its importance is widely acknowledged from the viewpoint of quality of care. However, there is limited research on the actual state of and ways to improve communication between nurses and patients in medical institutions and facilities for elderly people requiring care.

An examination of communication research related to medical care and nursing revealed that terms such as patientcentered communication, which has been drawing attention in recent years, clinical or medical communication, health communication, and therapeutic communication are being used. There is a need to explore how these terms are defined and to understand the perspectives from which they been studied.

Person-centered (patient-centered) communication is a type of communication based on person-centered care and these terms are used synonymously in some literature. Personcentered care has drawn attention in recent years as a reaction to previous medical centrism, in which medical professionals made medical decisions based on the disease and the patients merely followed the medical guidance provided based on these decisions. Institute of Medicine IOM, in the United States, defined patient-centered care as "providing care that is respectful of and responsive to individual patient preferences, needs, and values, and ensuring that patient values guide all clinical decisions" [1]. However, Ronald M. Epstein et al. argued that it is unclear how patient-centered communication should be assessed, and they operationally defined the following four items: "(1) Eliciting and understanding the patient's perspective, concerns, ideas, expectations, needs, and feelings; (2) understanding the patient within his or her unique psychosocial context; (3) reaching a shared understanding of the problem and its treatment with the patient that is concordant with the patient's values; and (4) helping patients to share power and responsibility by involving them in choices to the degree that they wish" [2]. Thus, the communication skills necessary for patient-centered care focus on bringing out the patient's problems and issues, especially in the early stages, by understanding the patient's perspective on the disease and expressing empathy $[3,4]$. In recent years, research is being conducted in the field of nursing, on patient-centered care focusing on the quality of care, such as consideration and dignity $[5,6]$.

Regarding the definition of clinical communication, Peter Salmon and Bridget Young stated, "Clinical communication is the vehicle for most patient care and can represent a treatment in its own right" [7]. However, many studies have used the term without clearly defining it. Majority of the existing studies have focused on the method of communication between a doctor and patient [7,8]. Although medical communication is also used without being clearly defined in many studies, it is used synonymously with clinical communication [9].

Health communication focuses on public health in particular and it is positioned as a type of communication aimed at resolving health problems and issues [10,11].

There are a number of studies on communication between a nurse and patient, which focus on therapeutic communication. Therapeutic communication is defined as a process in which the nurse consciously influences a client or helps the client to a better understanding through verbal or nonverbal communication. Therapeutic communication involves the use of specific strategies that encourage the patient to express feelings and ideas and that convey acceptance and respect [12]. It comprises communication skills, including active listening, sharing empathy, using touch, focusing, giving information, etc [13].

Peplau once stated that the purpose of a nurse-patient relationship is different from that of a doctor-patient relationship, friendship, or peer relationship [14]. Joyce Travelbee also wrote that "the goal of communication in nursing is to confirm and satisfy the nursing needs of sick people" [15]. This way of thinking has spread widely in the approach toward nurse-patient communication. Moore E and Kuipers, L also stated that the nature of the relationship between medical staff and patients is different from that between patients and their relatives in that the former is, by definition, therapeutic [16].

This overview of communication research in the medical and nursing fields shows that previous communication research has focused on certain medical needs and nursing needs 
of patients and users, and communication has been positioned as a means of resolving these problems and issues, while its strategies were examined and its outcomes evaluated. These studies are extremely important as a response to patients in the acute or chronic stage of a disease or disorder, and to those requiring disease prevention and health promotion. However, we believe a way of communication that takes into consideration the inherent meaning communication holds for humans needs to be explored when examining communication for the elderly, especially for those who have no choice but to live in institutions for a prolonged period and for those in the final stage of life.

In a previous fact-finding survey on the verbal communication that takes place during the course of a day between the elderly residing in long-term care health facilities and their caregivers (hereinafter abbreviated as staff), the authors found that there are two types of communication. One is "task-performatory communication" (hereinafter abbreviated as Type I communication), which pertains to various nursing and caregiving operations that assist the elderly in performing tasks of daily living. This accounted for $75.9 \%$ of the entire communication. The other was "life-worldly communication" (hereinafter abbreviated as Type II communication), which concerns family, work, and social events that are performed daily as a part of the elderly person's social life [17].

The average daily utterance duration of the elderly was 249.3 seconds (SD = 225.7), approximately 4.1 minutes, which is remarkably short. Further, 145.3 seconds $(S D=141.0)$ of this was dedicated to Type I utterances. The average duration of each utterance was as short as 3.24 seconds. Spontaneous utterance was extremely rare in Type I utterances [18]. This study revealed the actual state of communication by the elderly living in elderly care facilities as their final homes.

We examined the reasons for this short utterance duration considering the following three viewpoints: (1) utterance ordering and characteristics of utterance order, (2) characteristics of conversation content, and (3) characteristics of utterance length, and obtained the following results [19].

In Type I communication, it was found that all conversations were started by the staff, the topic of the conversation was introduced by a closed question, and the staff took the initiative in the conversation. These conversations allowed the staff to complete their tasks and, therefore, utterance by the elderly was controlled by the staff. For the elderly, this type of communication led to mere compliance with the instructions of the staff with short responses such as yes or no. Thus, utterances by the elderly were limited and communication was structured such that there was little scope for spontaneous utterances in Type I communication. The short utterance duration by the elderly during the course of the day is due to the fact that this kind of conversation comprises $76 \%$ of the conversations that take place between the staff and the elderly.

Although Type II utterances occurred for an average of 106.2 seconds ( $S D=155.5$ ), the duration of spontaneous utterance was longer in Type II utterances than it was in Type
I utterances. Similar to that done for Type I communication, we examined Type II communication using conversation analysis and obtained the following results [19].

When the topic presented by the staff pertained to the living world of the elderly, the elderly would start speaking spontaneously and they were able to expand on the conversation. This may have occurred because the elderly were treated as "narrators" by the staff; they took the elderly's responses seriously; and showed support by smiling, expressing agreement, showing a strong interest, etc. In Type II communication, because the person that takes the initiative in the conversation varies depending on the topic, the flexibility of the conversation increases, which leads to a two-way conversation that is similar to everyday conversations.

Our survey also revealed that the staff regarded Type II communication as idle talk and did not consider it a part of nursing operations [18]. This is likely based on the conventional way of thinking that views the nurse-patient relationship as a therapeutic relationship. However, is it possible that the fulfillment of nursing needs, which is the purpose of communication in a therapeutic relationship, may be viewed from the perspective of health support, in a limited sense, such as from the perspective of treatment and prevention of disease and disorder? We believe that, depending on the subject, it may be necessary to convert the purpose of communication into health support in a broader sense, as evident from WHO's definition of health (Health is a state of complete physical, mental and social well-being and not merely the absence of disease or infirmity). We believe that, in order to enrich the remaining days of the elderly and of people in the final stage of their life, it is important to offer them opportunities to engage in communication that enables these people, who are social beings, to lead a normal daily life.

\section{References}

1. The $21^{\text {st }}$ Century. Institute of Medicine (US) Committee on Quality of Health Care in America. Washington (DC): National Academies Press (US); 2001.

2. Epstein RM, Franks P, Fiscella K, Shields CG, Meldrum SC, Kravitz RL. Measuring patient-centered communication in Patient Physician consultations: Theoretical and practical issues. Soc Sci Med. 2005;61(7):1516-1528.

3. Agency for Healthcare Research and Quality (AHRQ). Training to Advance Physicians' Communication Skills.

4. Mead N, Bower P. Measuring patient-centeredness: a comparison of three observation-based instruments, Patient Educ Couns. 2000;39(1):71-80.

5. Dewar B, Noran M. Caring about Caring: Developing a model to implement compassionate relationship centered care in an older people care setting. Int J Nurs Stud. 2013;50(9):1247-1258.

6. Zainab Zahran, Marcelle Tauber, Holly Howe Watson, et al. Systematic review: What interventions improve dignity for older patients in hospital? J Clin Nurs. 2016;25(3-4):311-321.

7. Salmon P, Young B. Creativity in clinical communication: From communication skills to skilled communication, Med Educ. 2011;45(3):217-226. 
8. Hani Atwa, Asmaa Abdel Nasser. Physicians' self-assessment in intercultural clinical communication in Jeddah, Saudi Arabia, Education in Medicine Journal, 2016;8(2):15-26.

9. Aggarwal NK, Desilva R, Nicasio AV, Boiler M, Lewis-Fernández R. Does the cultural formulation interview for the fifth revision of the diagnostic and statistical manual of mental disorders (DSM-5) affect medical communication? A qualitative exploratory study from the New York site. Ethn Health. 2015;20(1):1-28. doi:10.1080/13557858. 2013.857762

10. Centers for Disease Control and Prevention (CDC). What is health communication? 2011.

11. Roxanne Parrott. Emphasizing "Communication" in health communication, International Communication Association 2004;54(4):751-787

12. Mosby's Medical Dictionary, 9th edition. (C) 2009, Elsevier.

13.Esmeralda Sherko, Eugjen Sotiri, Erinda Lika. Therapeutic communication, European Journal of Bioethics. 2013;4(7):457-466.
14. Anita W. O'Toole, Sheila R. Welt. Peplau's nursing theory, Tokyo: IgakuShoin, 2013.

15. Joyce Travel be. Interpersonal aspects of nursing, Edition 2, Philadelphia: F.A. Davis Company, 1971.

16. Moore E, Kuipers L. Behavioral correlates of expressed emotion in staff-patient Interactions. Soc Psychiatry Psychiatr Epidemiol. 1992;27(6):298-303.

17. Yasuko Fukaya, Kazuko Suzuki, Keiko Sichita. Predictors and correlates of the frequency and the length of verbal communications between nursing staff and elderly residents in geriatric care facilities. Jpn J Nurs Sci. 2003;1(2):107-115

18. Yasuko Fukaya, Sachiyo Koyama, Yusuke Kimura, Takanori Kitamura. Education to promote verbal communication by caregivers in geriatric care facilities, Jpn J Nurs Sci. 2009;6(2):91-103.

19. Yasuko Fukaya, Takanori Kitamura, Sachiyo Koyama, Kana Yamakuma, Shinobu Sato. Analysis of utterances by older persons in 'life-worldly' communication with caregivers in Japan. Journal of Nursing and Care. 2016;5(5) 